\title{
Salvia miltiorrhiza treatment during early reperfusion reduced postischemic myocardial injury in the rat
}

\author{
Ruqiong Nie, Rui Xia, Xingwu Zhong, and Zhengyuan Xia
}

\begin{abstract}
Oxidative stress may play a causative role in myocardial ischemia-reperfusion injury. However, it is a relatively understudied aspect regarding an optimal timing of antioxidant intervention during ischemia-reperfusion. The present study investigates the effect of different treatment regimens of Salvia miltiorrhiza (SM) herb extracts containing phenolic compounds that possess potent antioxidant properties on postischemic myocardial functional recovery in the setting of global myocardial ischemia and reperfusion. Langendorff-perfused rat hearts were subjected to $40 \mathrm{~min}$ of global ischemia at $37{ }^{\circ} \mathrm{C}$ followed by $60 \mathrm{~min}$ of reperfusion, and were randomly assigned into the untreated control and 2 SM-treated groups ( $n=7$ per group). In treatment 1 (SM1), $3 \mathrm{mg} / \mathrm{mL}$ of water soluble extract of SM was given for 10 min before ischemia and continued during ischemia through the aorta at a reduced flow rate of $60 \mu \mathrm{L} / \mathrm{min}$, but not during reperfusion. In treatment 2 (SM2), SM (3 mg/mL) was given during the first $15 \mathrm{~min}$ of reperfusion. During ischemia, hearts in the control and $\mathrm{SM} 2$ groups were given physiological saline at $60 \mu \mathrm{L} / \mathrm{min}$. The SM1 treatment reduced the production of $15-\mathrm{F}_{2 \mathrm{t}}-\mathrm{isoprostane}_{\mathrm{s}}$ a specific index of oxidative stress-induced lipid peroxidation, during ischemia $(94 \pm 20,43 \pm 6$, and $95 \pm 15 \mathrm{pg} / \mathrm{mL}$ in the coronary effluent in control, SM1, and SM2 groups, respectively; $p<0.05$, SM1 vs. control or SM2) and postponed the onset of ischemic contracture. However, SM2, but not the SM1 regimen, significantly reduced $15-\mathrm{F}_{2 \mathrm{t}}$-isoprostane production during early reperfusion and led to optimal postischemic myocardial functional recovery (left ventricular developed pressure $51 \pm 4,46 \pm 4$, and $60 \pm 6 \mathrm{mmHg}$ in the control, SM1, and SM2 groups, respectively, at $60 \mathrm{~min}$ of reperfusion; $p<0.05$, SM2 vs. control or SM1) and reduced myocardial infarct size as measured by triphenyltetrazolium chloride staining $(26 \% \pm 2 \%, 22 \% \pm 2 \%$, and $20 \% \pm 2 \%$ of the total area in the control, SM1, and SM2 groups, respectively, $p<0.05$, SM2 vs. control). It is concluded that $S$. miltiorrhiza could be beneficial in the treatment of myocardial ischemic injury and the timing of administration seems important.
\end{abstract}

Key words: Salvia miltiorrhiza, myocardial ischemia reperfusion, $15-\mathrm{F}_{2 \mathrm{t}}$-isoprostane.

Résumé : Le stress oxydatif pourrait être un facteur déterminant dans la lésion d'ischémie-reperfusion myocardique. Toutefois, cet aspect est relativement négligé en ce qui touche le moment optimal de l'intervention antioxydante durant l'ischémie-reperfusion. La présente étude examine l'effet de différents schémas de traitement avec des extraits de Salvia miltiorrhiza (SM), qui contiennent des composés phénoliques dotés de puissantes propriétés antioxydantes, sur le rétablissement de la fonction myocardique post-ischémique dans le contexte d'une ischémie myocardique globale suivie d'une reperfusion. Des cœurs de rats perfusés selon la méthode de Langendorff ont été soumis à une ischémie globale à $37^{\circ} \mathrm{C}$ durant $40 \mathrm{~min}$ et à une reperfusion durant $60 \mathrm{~min}$, puis ont été répartis aléatoirement dans le groupe témoin non traité et dans deux groupes traités avec SM ( $n=7$ par groupe). Dans le traitement 1 (SM1), $3 \mathrm{mg} / \mathrm{mL}$ d'extrait aqueux soluble de SM ont été administrés pendant 10 min avant et durant l'ischémie à travers l'aorte, à raison de $60 \mu \mathrm{L} / \mathrm{min}$, mais pas durant la reperfusion. Dans le traitement 2 (SM2), SM (3 mg/mL) a été a été administré durant les premières 15 min de la reperfusion. Durant l'ischémie, les cœurs des groupes témoin et SM2 ont été perfusés avec une solution saline, à raison de $60 \mu \mathrm{L} / \mathrm{min}$. Le traitement SM1 a réduit la production de $15-\mathrm{F}_{2 \mathrm{t}}$-isoprostane, un indice spécifique de la peroxydation lipidique induite par le stress oxydatif, durant l'ischémie $(94 \pm 20 \mathrm{pg} / \mathrm{mL}, 43 \pm 6 \mathrm{pg} / \mathrm{mL}$ et $95 \pm 15 \mathrm{pg} / \mathrm{mL}$ dans l'effluent coronaire des groupes témoin, SM1 et SM2, respectivement; $p<0,05$, SM1 vs témoin ou SM2) et retardé le début de la contracture ischémique. Toutefois, le traitement SM2, mais pas de SM1, a réduit significativement la production de $15-\mathrm{F}_{2 t^{-}}$ isoprostane durant la reperfusion précoce, et conduit à un rétablissement optimal de la fonction myocardique postischémique (pression développée ventriculaire gauche : $51 \pm 4 \mathrm{mmHg}, 46 \pm 4 \mathrm{mmHg}$ et $60 \pm 6 \mathrm{mmHg}$ chez les groupes té-

Received 21 June 2007. Published on the NRC Research Press Web site at cjpp.nrc.ca on 27 October 2007.

R. Nie. Department of Cardiology, Second Affiliated Hospital, Sun Yat-sen University, Guangzhou, Guangdong, China.

R. Xia. ${ }^{1}$ Anesthesiology Research Laboratory, Department of Anesthesiology, Renmin Hospital, Wuhan University, Wuhan, Hubei 430060, China.

X. Zhong. State Key Laboratory of Ophthalmology and Zhongshan Ophthalmic Center, Sun Yat-sen University, Guangzhou, Guangdong, China.

Z. Xia. ${ }^{2}$ Anesthesiology Research Laboratory, Department of Anesthesiology, Renmin Hospital, Wuhan University, Wuhan, Hubei 430060, China; Department of Anesthesiology, University of Hong Kong, Hong Kong, China.

${ }^{1}$ Present address: Department of Anesthesia, First Affiliated Hospital of Yangtze University, Hubei, China.

${ }^{2}$ Corresponding author (e-mail: zhengyuan_xia@yahoo.com). 
moin, SM1 et SM2, respectivement, après 60 min de reperfusion; $p<0,05$, SM2 vs témoin ou SM1) et réduit la taille de l'infarctus du myocarde, comme mesuré par la coloration avec le chlorure de triphényltétrazolium (26 $\pm 2 \%, 22 \pm 2 \%$ et $20 \pm 2 \%$ de la surface totale chez les groupes témoin, SM1 et SM2, respectivement; $p<0,05$, SM2 vs témoin). On conclut que $S$. miltiorrhiza pourrait être bénéfique dans le traitement de la lésion ischémique myocardique et que le moment de l'administration serait important.

Mots-clés : Salvia miltiorrhiza, ischémie-reperfusion du myocarde, 15- $\mathrm{F}_{2 \mathrm{t}}$-isoprostane.

[Traduit par la Rédaction]

\section{Introduction}

Salvia miltiorrhiza (SM, also known as danshen or tanshen) is a plant that has been used extensively as a traditional medicine for treating cardiovascular diseases in China and Japan. The aqueous extract of SM contains mainly phenolic compounds such as salvianolic acid A and B, rosmarinic acid, and 3,4-dihydroxyphenyl lactate (danshensu) (Fig. 1) (Zhou et al. 2005), which have been shown to possess potent free-radical scavenging properties (Liu et al. 1992; Zhou and Ruigrok 1990). The administration of water soluble extraction of SM has been found to reduce the size of myocardial infarction induced by ischemia and reperfusion in both isolated and intact rabbit hearts (Wu et al. 1993; Fung et al. 1993). Water soluble extraction of SM was also found to increase the recovery of left ventricular developed pressure and attenuate the elevation in enddiastolic pressure during the postischemic reperfusion of isolated rat hearts (Zhou and Ruigrok 1990; Yagi et al. 1989). However, in these studies (Wu et al. 1993; Fung et al. 1993; Zhou and Ruigrok 1990; Yagi et al. 1989), only a single SM treatment regimen was incorporated. Little is known about whether SM could confer cardioprotection when administrated to the myocardium before and during ischemia.

Oxidative stress has been strongly implicated in myocardial ischemia-reperfusion injury (IRI) (Das and Maulik 2006; Neuzil et al. 2005). Reactive oxygen species (ROS) formation, primarily during reperfusion, was previously thought responsible for IRI, but the importance of ROS formation during ischemia has recently been emphasized. Recent studies have demonstrated significantly increased levels of $15-\mathrm{F}_{2 \mathrm{t}}$-isoprostane $\left(15-\mathrm{F}_{2 \mathrm{t}}\right.$-IsoP), a sensitive and reliable index of in vivo oxidative stress-induced lipid peroxidation (Morrow and Roberts 1997), during the phase of myocardial ischemia and early reperfusion (Ulus et al. 2003; Mehlhorn et al. 2003). We have recently shown that the ischemic heart is a source of $15-\mathrm{F}_{2 \mathrm{t}}$-IsoP generation (Xia et al. 2003a, 2003b), and that $15-\mathrm{F}_{2 \mathrm{t}}$-IsoP plays a causative role in mediating myocardial IRI in the isolated rat hearts (Xia et al. 2005). Therefore, we hypothesized that $\mathrm{SM}$, when administrated before and during myocardial ischemia, should reduce $15-\mathrm{F}_{2 \mathrm{t}}$-IsoP generation during ischemia and may confer similar or better cardioprotective effects than its administration being initiated during reperfusion in isolated ischemic reperfused rat hearts.

\section{Materials and methods}

\section{Heart preparation}

This study was approved by the institutional Committee of Animal Care. The investigation conforms to the Guide for the Care and Use of Laboratory Animals published by the US National Institutes of Health (NIH Publication No. 85-23, revised 1996). Male Sprague-Dawley rats (280$320 \mathrm{~g})$ were anesthetized with pentobarbital $(70 \mathrm{mg} / \mathrm{kg}$, i.p. $)$ and heparinized with sodium heparin (1000 IU/kg, i.p.). After median sternotomy, hearts were quickly excised and immersed in ice-cold Krebs-Henseleit (KH) solution to stop contractions. Hearts were gently squeezed to remove residual blood and prevent clot formation. They were then retrogradely perfused via the aorta in a nonworking Langendorff preparation at a constant flow rate of $10 \mathrm{~mL} / \mathrm{min}$ by using a peristaltic pump. The perfusion flow rate $(10 \mathrm{~mL} / \mathrm{min})$ was based on the result of a pilot study showing that isolated hearts beat well and remain hemodynamically stable for $120 \mathrm{~min}$ (the duration of the experiment) in our experimental set-up when perfused with $\mathrm{KH}$ without inducing ischemia. The perfusion fluid $\left(\mathrm{pH} \mathrm{7.4,} 37{ }^{\circ} \mathrm{C}\right)$ was $\mathrm{KH}$ solution that contained (in mmol/L): $\mathrm{NaCl}, 118 ; \mathrm{NaHCO} 3,24 ; \mathrm{KCl}$, 4.63; $\mathrm{MgCl} 2,1.2 ; \mathrm{CaCl} 2,1.25 ; \mathrm{KH} 2 \mathrm{PO} 4,1.17$; and glucose, 11. The perfusate was bubbled with a mixture of $95 \% \mathrm{O}_{2}$ and $5 \% \mathrm{CO}_{2}$. Temperatures of the perfusate solution and of the chamber in which the hearts were held were maintained at $37{ }^{\circ} \mathrm{C}$ by using a thermostatically controlled watercirculating system.

Coronary perfusion pressure (CPP) was measured via a side arm of the perfusion cannula connected to a pressure transducer, as previously described (Xia et al. 2003b, 2004). A latex water-filled balloon fixed to a pressure transducer was inserted through the mitral valve into the left ventricle for the determination of left ventricular (LV) developed pressure (LVDP), which was calculated by subtracting enddiastolic pressure (LVEDP) from LV peak systolic pressure (LVSP). LVEDP was adjusted to approximately $5 \mathrm{mmHg}$ before the start of the experiment by adjusting the volume in the intraventricular balloon. Exclusion criteria included heart preparation times longer than $60 \mathrm{~s}$ and (or) LVSP lower than $65 \mathrm{mmHg}$ after $10 \mathrm{~min}$ of equilibration.

\section{Experimental protocol}

All hearts were initially equilibrated for $10 \mathrm{~min}$ (baseline, BS). They were then randomly assigned to 1 of the 3 experimental groups: ischemia-reperfusion untreated control (control, $n=7$ ), SM pretreatment group (group SM1, $n=7$ ), and $\mathrm{SM}$ posttreatment group (group SM2, $n=7$ ). After BS, hearts in the SM1 group were perfused with $\mathrm{KH}$ containing $3 \mathrm{mg} / \mathrm{mL}$ of the purified aqueous extract of SM $(1.5 \mathrm{~g} / \mathrm{mL}$, Lot number 0405172, Chiatai Qingchunbao Pharmaceutical Co., Ltd, Hangzhou, China) in the perfusate for $10 \mathrm{~min}$ before global ischemia (40 min) was induced by stopping per- 
Fig. 1. Molecular structures of 4 bioactive ingredients purified from Salvia miltiorrhiza.

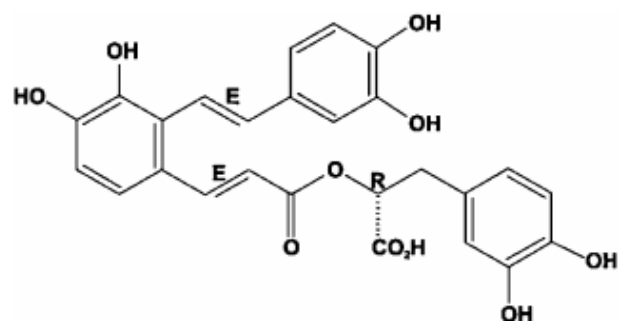

Salvianolic acid A

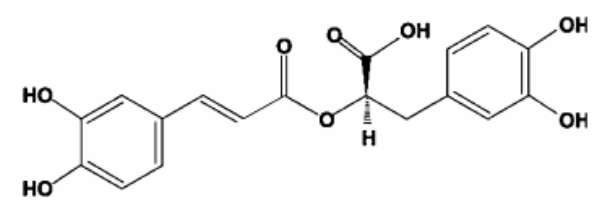

Rosmarinic acid

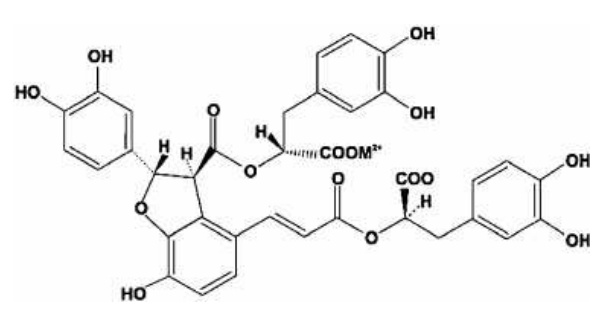

Salvianolic acid B

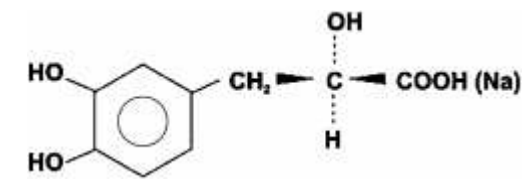

3,4-dihydroxyphenyl lactate fusion. The SM was provided as a concentrate that was subsequently diluted into the perfusate at the concentration (3 $\mathrm{mg} / \mathrm{mL}$ ) mentioned above. The SM concentration (3 $\mathrm{mg} / \mathrm{mL}$ ) was chosen based on a recent study showing that $\mathrm{SM}$ at $3 \mathrm{mg} / \mathrm{mL}$ attenuates anoxia and reoxygenationinduced cellular injury in the isolated rat ventricular cardiomyocytes (Cao et al. 2003). Hearts in the control and the SM2 groups underwent an additional 10 min period of equilibration before global ischemia was induced. During ischemia, saline (control and SM2 groups) or SM at $3 \mathrm{mg} / \mathrm{mL}$ in saline solution (group SM1) was perfused through the aorta at $60 \mu \mathrm{L} / \mathrm{min}$ by using a mini-pump. $\mathrm{KH}$ was perfused during $60 \mathrm{~min}$ of reperfusion in both the control and the SM1 groups. In the SM2 group, hearts were perfused with $\mathrm{SM}$ at $3 \mathrm{mg} / \mathrm{mL}$ in $\mathrm{KH}$ during the first $15 \mathrm{~min}$ of reperfusion followed by perfusion with $\mathrm{KH}$ alone for $45 \mathrm{~min}$. Hearts were electrically paced at a rate of 300 beats/min before and after, but not during, the ischemic period when hearts ceased to beat spontaneously.

Baseline effluent perfusate was sampled at BS (i.e., $10 \mathrm{~min}$ after equilibration). Effluent samples during ischemia were collected during the first $30 \mathrm{~min}$ of ischemia (isch) as described previously (Xia et al. 2003a). The choice of this initial first $30 \mathrm{~min}$ interval, rather than $40 \mathrm{~min}$, was largely based on the factor that most similar studies used a maximum of $30 \mathrm{~min}$ of global ischemia interval. So, it was aimed to make a potential comparison easier. Also, effluent was sampled for a duration of $0.5 \mathrm{~min}$ (which yielded $5 \mathrm{~mL}$ ), respectively, at $0.5-1$ (Re-1), 4.5-5 (Re-5), 29.5-30 (Re-30), and 59.5-60 (Re-60) min of reperfusion in the 3 experimental groups. Aliquots of the effluent samples were immediately stored at $-70{ }^{\circ} \mathrm{C}$ for later analysis for cardiac specific creatine kinase (CK-MB) in all study groups. Another portion of the effluent sample was initially concentrated (see next section) and then stored at $-70{ }^{\circ} \mathrm{C}$ for analysis of endothelin-1 (ET-1) concentration. At the end of the $60 \mathrm{~min}$ of reperfusion, $1 \%$ 2,3,5-triphenyltetrazolium chloride (TTC) at $37{ }^{\circ} \mathrm{C}$ in buffer $(0.1 \mathrm{~mol}$ phosphate/L buffer adjusted to $\mathrm{pH}$ 7.4) was pumped into the heart at $1 \mathrm{~mL}$ per min for 15 min until the epicardial surface became deep red. The average TTC perfusion rate was $1.08 \pm 0.04 \mathrm{~mL} / \mathrm{g}$ tissue. After the completion of TTC staining, the hearts were weighed and then stored in $10 \%$ formaldehyde for later analysis of myocardial infarct size.

\section{Measurement of $15-\mathrm{F}_{2 \mathrm{t}}$-isoprostane}

Effluent free $15-\mathrm{F}_{2 \mathrm{t}}$-IsoP levels were measured by using a commercial enzyme-linked immunoassay kit (Cayman Chemical, Ann Arbor, Mich.) as detailed previously (Xia et al. 2003a, 2003b). The samples were coded and the investigator responsible for $15-\mathrm{F}_{2 \mathrm{t}}$-IsoP assays was blinded until the completion of the assay.

\section{Measurement of ET-1}

Measurement of ET-1 concentrations in the coronary effluent was performed by using a commercially available human ET-1 enzyme immunometric assay kit (human ET-1 EIA kit 900-020, Assay Designs Inc., Ann Arbor, Mich.) as detailed previously (Xia et al. 2005). The assay kit detects ET-1 levels in biological fluids of human, bovine, canine, murine, porcine, and rat samples (Wang and Wang 2004). On the basis of pilot studies, ET-1 concentrations in perfusate samples were often below the ET-1 sensitivity of the assay $(0.14 \mathrm{pg} / \mathrm{mL})$. Therefore, effluent samples collected during both ischemia and reperfusion were concentrated 4-fold by evaporation of solvent (i.e., KH) at room temperature under a stream of dry nitrogen. ET-1 concentration was calculated as a quarter of the measured ET-1 level in the concentrated sample. The accuracy of this approach was confirmed by prior testing using known ET-1 standards that yielded a recovery rate of $96.5 \% \pm 1.2 \%(n=5)$. The assays plates were read at $450 \mathrm{~nm}$, and the values of the unknowns were expressed as picograms of ET-1 per millilitre of effluent.

\section{Measurement of CK-MB}

Measurement of CK-MB was performed by using a commercially available enzyme immunoassay kit (Catalog num- 
Fig. 2. Concentrations during myocardial ischemia-reperfusion of (A) effluent 15- $\mathrm{F}_{2 \mathrm{t}}$-isoprostane, (B) endothelin-1 (ET-1), and (C) CK-MB (cardiac specific creatine kinase). Baseline (BS) and ischemia (isch) indicate $10 \mathrm{~min}$ after stabilization and $30 \mathrm{~min}$ during global ischemia, respectively; Re-1, Re-5, Re-30, and Re-60 indicate $1,5,30$, and $60 \mathrm{~min}$ after reperfusion, respectively. Since the levels of $15-\mathrm{F}_{2 \mathrm{t}}$-isoprostane, ET-1, and CK-MB during ischemia might reflect the slow perfusion rate and hence the ability to accumulate high concentrations, their levels during ischemia and reperfusion were expressed as values (picograms, or nanograms, per millilitre per minute) for convenient comparison. ${ }^{*}, p<0.05$ vs. BS; ${ }^{\#}, p<0.05$ vs. control.
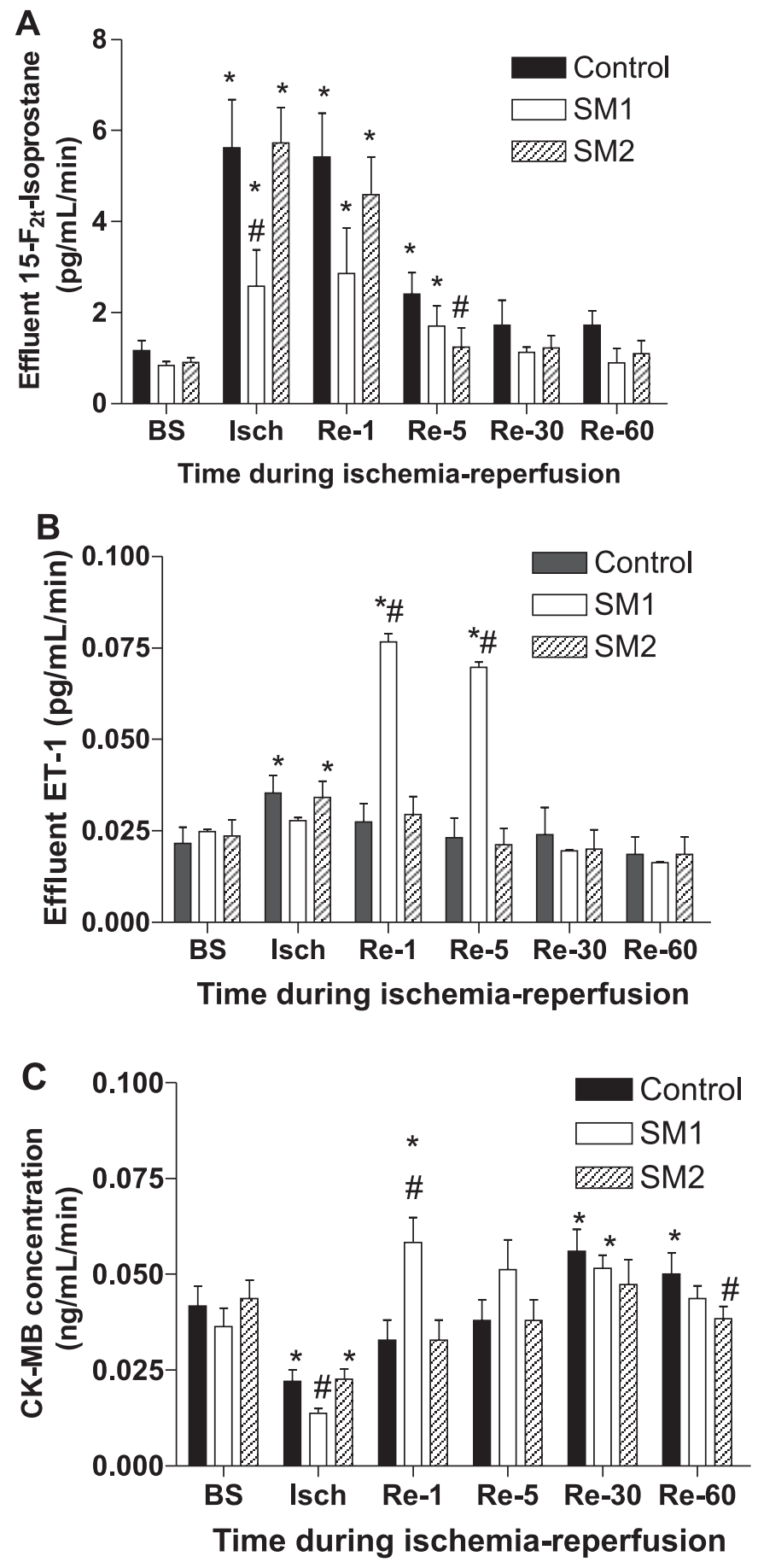

ber BC-1121, BioCheck Inc., Foster City, Calif.) as described previously (Xia et al. 2005). The values of the unknowns were expressed as nanograms of CK-MB per millilitre of effluent.

\section{Infarct size measurement}

The measurement of infarct size was essentially identical to that described by Qin et al. 2004 except for the method of quantification. After the TTC reaction, the hearts were sectioned transaxially and size of infarct was evaluated as percentage of sectional area of infarcted tissue to the sectional area of the whole heart in 1-millimetre layers (5 layers, LG scanner) as previously reported (Xia et al. 2005). Morphometric measurements of infarct size were performed with a LG scanner and 6.0 CE software. The histogram counts of the red (viable) and white (infarcted) tissue were recorded. The percentage infarction was calculated as white counts divided by the sum of the red plus white counts.

\section{Statistical analysis}

All data are presented as means \pm SEM. Cardiac variables and chemical assay parameters were compared by two-way ANOVA with Bonferroni correction (GraphPad Prism). One-way repeated ANOVA and Tukey's multiple comparison tests were applied for within-group comparison. $p<$ 0.05 was considered statistically significant.

\section{Results}

\section{Body and heart mass}

The animals' body mass $(302.1 \pm 5.5,303.0 \pm 4.7$, and $300.5 \pm 5.9 \mathrm{~g}$, respectively, in the control, SM1, and SM2 groups $)$ and heart mass $(0.92 \pm 0.03,0.99 \pm 0.05$, and $0.91 \pm 0.04 \mathrm{~g}$, respectively, in the control, SM1, and SM2 groups) did not differ among groups $(p>0.1)$.

\section{$15-F_{2 t}$-IsoP generation during ischemia-reperfusion}

As shown in Fig. 2A, at $\mathrm{BS}, 15-\mathrm{F}_{2 \mathrm{t}}$-IsoP values did not differ among groups. During ischemia, 15- $\mathrm{F}_{2 \mathrm{t}}$-IsoP levels were lower in the SM1 group than in the control $(p<0.05)$. At Re-1, effluent $15-\mathrm{F}_{2 \mathrm{t}}$-IsoP concentrations in the SM1 group tended to be lower than that in the control group, but the difference did not reach statistical significance $(p>0.1)$. During early reperfusion, level of effluent $15-\mathrm{F}_{2 \mathrm{t}}$-IsoP concentrations decreased $74 \%$ in the SM2 group, $54 \%$ in the control, and $38 \%$ in the SM1 group from Re-1 to Re-5. At Re-5, levels of $15-\mathrm{F}_{2 \mathrm{t}}-\mathrm{IsoP}$ in the SM2 group, but not in the control and SM1 groups, decreased to baseline levels $(p>$ 0.05 vs. BS). Effluent $15-\mathrm{F}_{2 \mathrm{t}}$-IsoP returned to baseline levels at $\mathrm{Re}-30$ and onwards in all groups.

\section{Effluent ET-1 release during ischemia and reperfusion}

Baseline effluent ET-1 concentrations did not differ among groups $(p>0.1$, Fig. $2 \mathrm{~B})$. ET-1 increased during ischemia in the control groups $(p<0.05$ vs. BS). It was about $28 \%$ lower in the SM1 group relative to the control, but this difference did not reach statistical significance $(p>0.05$, Fig. 2B). ET-1 values at Re-1 in the control and SM2 groups were about 1.25-fold of their baseline levels, respectively, but did not significantly differ from BS $(p>0.1 \mathrm{Re}-1$ vs. BS). Unexpectedly, ET-1 values at Re-1 and Re-5 in the 
Fig. 3. Variations of left ventricular end-diastolic pressure (LVEDP) reflecting myocardial stiffness during reperfusion (A), and recovery of left ventricular developed pressure (LVDP) reflecting effective myocardial contractility during reperfusion (B). Baseline (BS) and preischemia values indicate $10 \mathrm{~min}$ after stabilization and the time immediately before ischemia, respectively; Re-10, Re30 , and Re-60 indicate 10, 30, and $60 \mathrm{~min}$ after reperfusion, respectively. For both A and $\mathrm{B}, *, p<0.05$ vs. BS; \# $p<0.05$ vs. control.

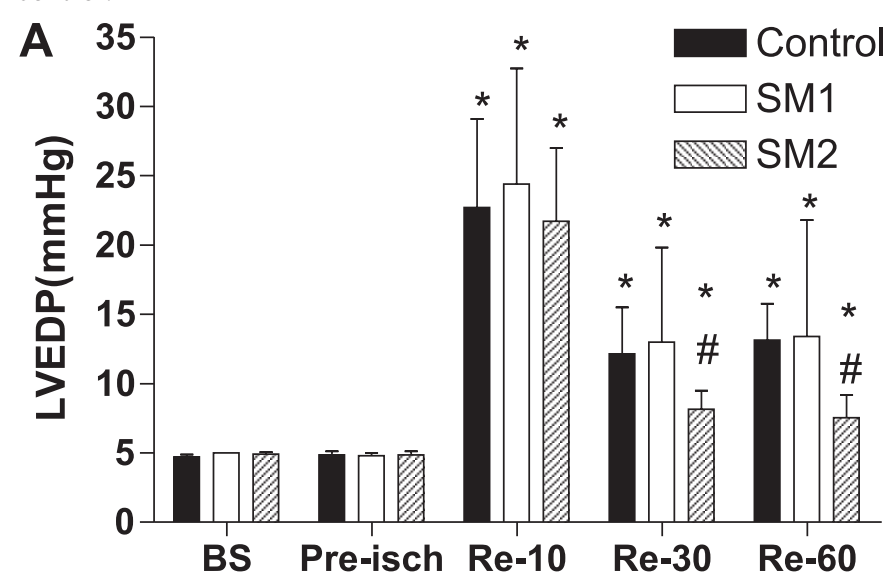

Time pints before and after reperfusion

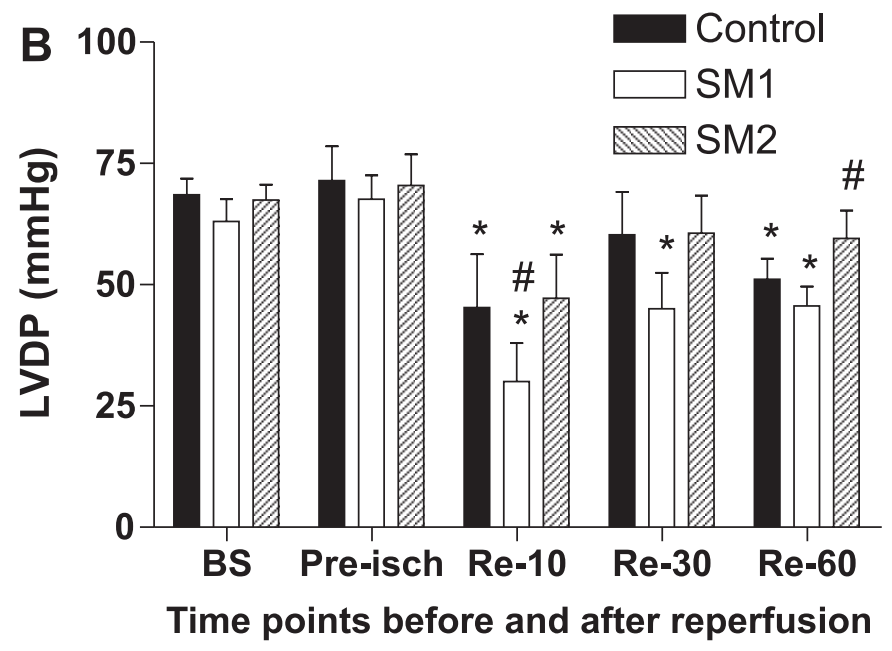

SM1 group were about 2.5-fold of its baseline value ( $p<$ 0.05 vs. BS), and were significantly higher than the corresponding values in the control group $(p<0.05)$.

\section{CK-MB release during ischemia-reperfusion}

Baseline CK-MB release was detectable in this model and did not differ among groups (Fig. 2B). During ischemia, CK-MB levels were lower relative to the baseline values the control and SM2 groups ( $p<0.05$ vs. BS), which may indicate that the very low flow of saline solution given during ischemia could only reach part of the myocardium adjacent to the coronary vasculature. CK-MB release during ischemia was significantly lower in the SM1 group compared with control $(p<0.05)$. Unexpectedly, significant increase of CK-MB during early reperfusion at Re-1 was seen in the SM1 group, but not in the control and SM2 groups. $\mathrm{CK}-\mathrm{MB}$ levels increased during reperfusion in the control
Fig. 4. Variations of coronary perfusion pressure (CPP) before ischemia and during postischemic reperfusion. Baseline (BS) and preischemic values indicate $10 \mathrm{~min}$ after stabilization and the time immediately before ischemia, respectively; Re-10, Re-30, and Re60 indicate 10, 30, and $60 \mathrm{~min}$ after reperfusion, respectively. *, $p<0.05$ vs. BS; \#, $p<0.05$ vs. control.

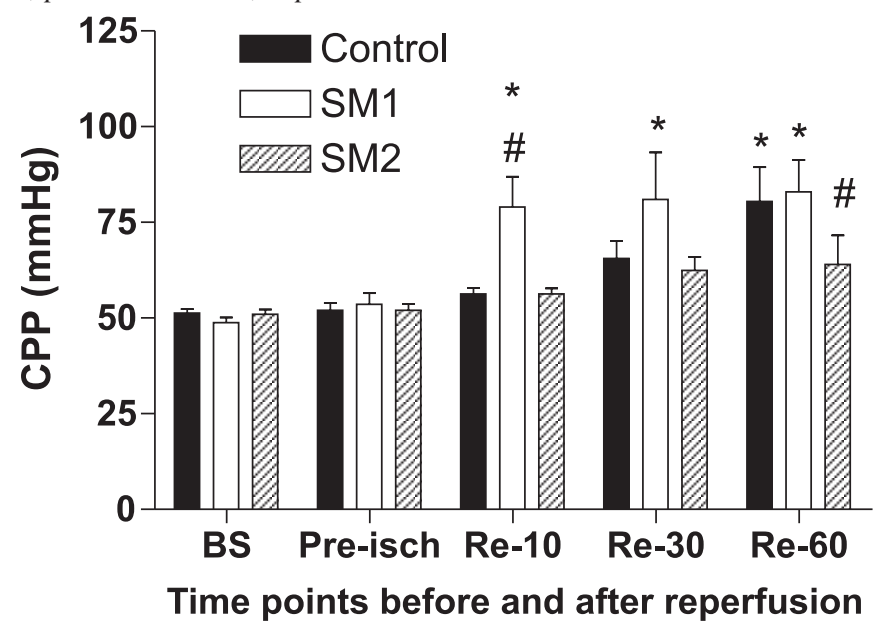

Fig. 5. Myocardial infarct size following $40 \mathrm{~min}$ of global ischemia and 60 min of reperfusion. SM1 and SM2 indicate Salvia miltiorrhia (SM) treatment regimens 1 and 2 , respectively; *, $p<0.05$ vs. control.

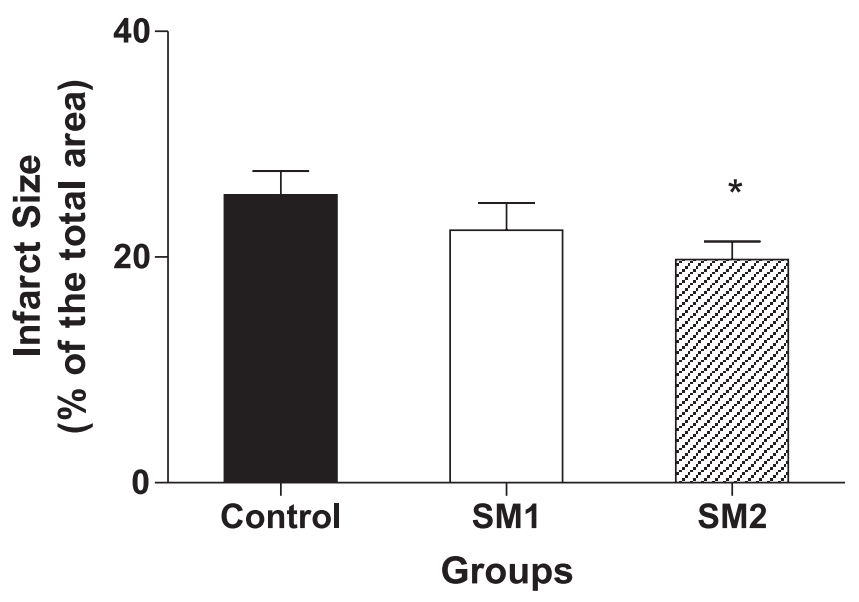

group, reached statistical significance at Re-30 compared with baseline ( $p<0.05$ vs. BS), and remained increased at $\mathrm{Re}-60$. SM2 prevented the significant increased of CK-MB seen in the control group during reperfusion. At Re-60, levels of CK-MB in the SM2 group, but not in the SM1 group, was lower than in that the control group $(p<0.05)$.

\section{Contracture development during ischemia}

The LVEDP increased progressively during ischemia in all the 3 experimental groups and neither the magnitude of LVEDP nor the peak contracture or time to peak contracture significantly differ among them (data not shown). However, time to the onset of ischemic contracture, defined as elevation of LVEDP $\geq 2.5 \mathrm{mmHg}$ above baseline value, was significantly longer in the SM1 group $(23.5 \pm 1.2 \mathrm{~min})$ than in the control group $(18.0 \pm 1.6 \mathrm{~min})$ and $\mathrm{SM} 2$ group $(17.5 \pm$ $1.7 \mathrm{~min})(p<0.05)$. 


\section{Functional response to ischemia-reperfusion}

During reperfusion, LVEDP in all the groups was significantly higher than the corresponding baseline values (Fig. 3A), which tended to decrease toward the end of reperfusion. SM2, but not SM1, significantly attenuated the elevation of LVEDP at Re-30 and Re-60 compared with control group $(p<0.05)$.

The LVDP in the control group recovered to a maximum of $87 \% \pm 12 \%$ of its baseline value at $\operatorname{Re}-30(p>0.05$ vs. BS, Fig. 3B) and decreased thereafter. The LVDP in the SM1 group was lower than that in the control group at Re$10(p<0.05)$ and gradually increased thereafter. The LVDP in the SM2 group recovered to $90 \% \pm 10 \%$ of its baseline value at Re-30 ( $p>0.05$ vs. BS, Fig. 3B) and maintained at this level thereafter. At Re-60, LVDP in the SM2 group, but not in the SM1 group, was significantly higher than that in the control group.

\section{Coronary perfusion pressure}

Coronary perfusion pressure (CPP) did not increase significantly until after $60 \mathrm{~min}$ of reperfusion in the untreated control group ( $p<0.05$ vs. BS, Fig. 4). CPP in the SM1 group rapidly increased during early reperfusion and was higher than that in the control group at Re-10. It remained elevated throughout reperfusion in the SM1 group $(p<0.05$ vs. baseline and control). In contrast, SM2 prevented the significant increase of CPP seen in the control group.

\section{Myocardial infarct size}

As shown in Fig. 5, myocardial infarct size in the untreated group was $25.5 \% \pm 2.1 \%(n=7$, range $21.5 \%-$ $32.0 \%)$. This infarct size is relatively smaller than that seen in ischemic-reperfused untreated hearts $(n=3,46.5 \% \pm$ $5.0 \%$, unpublished data) previously studied under the same experimental conditions (i.e., $40 \mathrm{~min}$ global ischemia followed by 60 min reperfusion) except that no saline solution was infused during the global ischemia. This is suggestive that the small volumes of saline infusion during ischemia in the current study may serve to wash out some toxic substances produced during ischemia, therefore attenuating myocardial injury. At $60 \mathrm{~min}$ postischemic reperfusion, the myocardial infarct size in the SM2 group $(19.8 \% \pm 1.6 \%)$, but not in the SM1 group $(22.4 \% \pm 2.4 \%)$ was significantly smaller than that in the control group ( $p<0.05$, Fig. 5).

\section{Discussion}

A novel, but somewhat surprising, finding of the current study is that SM administration before and during myocardial ischemia attenuated oxidative stress and myocardial cellular damage during ischemia, but followed by more severe cellular damage during the early phase of reperfusion in the isolated ischemic-reperfused rat hearts as compared with untreated control hearts. The $15-\mathrm{F}_{2 \mathrm{t}}$-IsoP formation and CK-MB release during ischemia in the SM1 group were lower than that in the control group accompanied with significantly delayed ischemic contracture onset time, suggestive of a cardioprotective effect of the SM1 treatment regimen during ischemia. However, the SM1 treatment regimen resulted in more severe myocardial cellular damage during early reperfusion manifested as significant increase of $\mathrm{CK}-\mathrm{MB}$ release at $\mathrm{Re}-1$ relative to control. Increased myocardial cellular damage seen in the SM1 group during early reperfusion might be attributable, in part, to the significant increase of CPP during early reperfusion, which might be either a cause and (or) a consequence of coronary artery endothelial cell damage.

A study has shown that coronary vascular endothelial cell injury occurs prior to cardiomyocyte injury in the isolated rat hearts subjected to $35 \mathrm{~min}$ of regional ischemia followed by up to $120 \mathrm{~min}$ of reperfusion (Scarabelli et al. 2001). Also, impairment of coronary vasodilation (microvascular "stunning") may persist for hours after a brief (15 min) reversible ischemia (Bolli et al. 1990). Hence, in the current study, the study agent SM diluted in saline was given at a very low infusion rate $(60 \mu \mathrm{L} / \mathrm{min})$ in the $\mathrm{SM} 1$ group during global ischemia, attempting to ameliorate vascular injury during and postischemia and subsequently attenuating myocardial IRI. This is based on the assumption that an agent perfused at this low infusion rate is unlikely to be able to reach the myocardium in significant amount, but rather mainly interacts with the vascular endothelium and as such may confer beneficial effects during myocardial ischemiareperfusion in this model (Xia et al. 2004). The relatively lower CK-MB levels in the effluent during ischemia compared with baseline in the control group (Fig. 2) might serve as an indirect evidence that saline solution perfused at a very low flow rate $(60 \mu \mathrm{L} / \mathrm{min})$ could only reach part of the myocardium adjacent to the coronary vasculature. It should be noted, however, this model does not exactly simulate the clinical scenario during cardiac surgery in which the agents are given as addictives to the cardioplegia. Therefore, caution has to be exercised when interpreting the results in clinical settings. Nevertheless, the current approach (infusing the agent alone at a very low rate during ischemia) avoided confounding the potential vascular protective effects of the cardioplegia.

The mechanism responsible for the increase of CPP during early reperfusion in the SM1 group is not very clear. Since we used constant flow rate perfusion in the current study, the increase of CPP should reflect the increased release or activity of vascular constrictive substances or decreased release or activity of vasodilators. Therefore, the dramatic increase of ET-1 during early reperfusion seen in the SM1 group should be responsible, at least in part, for the increase of CPP during early reperfusion. Given the antioxidant nature of SM (Cao et al. 2003), it seems difficult to understand that antioxidant therapy before and during myocardial ischemia should lead to the increase of ET-1 during early reperfusion. Whereas burst production of reactive oxygen species occurs during early reperfusion (Bolli et al. 1989), significant superoxide generation occurs in the cardiomyocyte during ischemia before reperfusion (Becker et al. 1999). We suspect that the generation of small amount of superoxide during early phase of ischemia may have exerted an "ischemic preconditioning (IPC)"-like protective effect. IPC refers to the ability of short periods of ischemia to render the myocardium more resistant to a subsequent ischemic insult, a phenomenon first identified by Murry and colleagues (Murry et al. 1986). The effects of IPC rely on the generation of small amount of superoxide to render an acute and delayed cardioprotection (Kevin et al. 2005; Pagliaro et 
al. 2001). The superoxide generated during preconditioning may prepare the heart to produce increased amount of endogenous antioxidant enzymes such as superoxide dismutase, which may serve to reduce the burst production of reactive oxygen species during reperfusion and attenuate postischemic myocardial dysfunction (Bolli et al. 1989). On the other hand, superoxide has been shown to inhibit endothelin-converting enzyme, the enzyme that cleaves big ET-1 into ET-1, and decrease ET-1 formation in the cultured bovine aortic endothelial cells (Lopez-Ongil et al. 2000). Therefore, the SM1 treatment regimen may have blocked the potential beneficial effects of superoxide generated before and especially during early phase of ischemia, which may have resulted in increased endothelinconverting enzyme activity, leading to the subsequent burst increase of ET-1 release during early reperfusion. This notion is indirectly supported by the most recent finding of Duda et al. (2007), which shows that IPC prevents the burst increase of ET-1 during reperfusion in the isolated ischemic-reperfused guinea-pig hearts. However, further study is needed to verify our hypothesis that superoxide generated during early phase of ischemia may confer beneficial effects.

Another interesting finding of the current study is that administration of SM solely during the early phase of reperfusion (SM2 group) prevented the increase of CK-MB and CPP during reperfusion seen in the control group, and ended up with accelerated postischemic myocardial functional recovery (Fig. 3B) and reduced myocardial infarct size (Fig. 5). The results are consistent with the notion that the first minutes of reperfusion is a window of opportunity for cardioprotection (Piper et al. 2004). CK-MB is a relatively more cardiac-specific isoenzyme of the creatine kinase family. However, it also exists in other tissues like the skeletal muscle and elevates when skeletal muscle injury occurs. The isolated heart preparation ensures that CK-MB elevation can be served as a specific marker of myocardial cellular damage. Similar to our previous study (Xia et al. 2005) and studies of others (Calabresi et al. 2003; Chocron et al. 1996), CK-MB concentration in the effluent perfusate was increased during postischemic reperfusion in the isolated rat hearts (Fig. 2C). To our knowledge, our study is the first to report that SM, when administrated solely during early reperfusion, reduces cardiac CK-MB release in the isolated ischemic-reperfused hearts, confirming its cardioprotective effects. It is worth noting that SM2 treatment led to faster reduction of $15-\mathrm{F}_{2 \mathrm{t}}$-IsoP concentration in the perfusate during early reperfusion. At Re-5, levels of $15-\mathrm{F}_{2 \mathrm{t}}$-IsoP in the SM2 group, but not in the control or SM1 group, decreased to a level comparable with the baseline values (Fig. 2), indicative of increased antioxidant potential in the SM2 group. Hence, enhancement of antioxidant potential during early reperfusion may represent a mechanism whereby SM2 facilitates postischemic myocardial functional recovery and reduced myocardial infarction. In addition to its antioxidant capacity, aqueous extracts of SM have been shown to dilate coronary artery by inhibition of calcium channels (Lam et al. 2007). The gradual increase of CPP during reperfusion seen in the control group suggests a gradual vascular closure in the isolated heart perfused under nonphysiological perfusion conditions (i.e., nonblood perfusion), which renders part of the myocardium to a hypoxic condition, resulting in increased $\mathrm{CK}-\mathrm{MB}$ release during reperfusion. Therefore, the cardioprotection seen in the SM2 group should be attributable, in part, to its coronary dilatory effects evidenced by significantly lower CPP at Re-60 compared with the control and SM1 group. On the contrary, the cardioprotective effects of SM1 manifested during ischemia (evidenced by reduced CK-MB release and delayed onset of ischemic contracture) may have been counteracted by the subsequent increase of ET-1 and CPP during reperfusion that caused increased postischemic myocardial cellular damage. This may explain why SM1 confers a neutral cardioprotective effect in terms of postischemic functional recovery despite the reduction of myocardial damage during ischemia.

In summary, we have shown that SM application before and during myocardial ischemia postponed, but did not significantly attenuate postischemic myocardial injury. The mechanism for this phenomenon is unclear and merits further studies. Application of SM during reperfusion reduced $15-\mathrm{F}_{2 \mathrm{t}}$-IsoP production during early reperfusion that led to optimal postischemic myocardial functional recovery and reduced myocardial infarct size. We conclude that S. miltiorrhiza could be beneficial in the treatment of myocardial ischemic injury and the timing of administration seems important. Results from this study may shed light on the mechanisms responsible for the conflict results of agents with antioxidant property such as the anesthetic propofol, which has been reported to be either beneficial (Xia et al. 2003a, 2003b; Kokita and Hara 1996) or not cardioprotective (Ross et al. 1998; Ebel et al. 1999) in various myocardial ischemia-reperfusion models.

\section{Acknowledgements}

This study is supported, in part, by a grant from Natural Sciences Foundation of Guangdon Province (No. 04009425, to R. Nie), and in part by a National Natural Science Foundation of China (NSFC) grant (No. 30471659, to Z. Xia).

\section{References}

Becker, L.B., vanden Hoek, T.L., Shao, Z.H., Li, C.Q., and Schumacker, P.T. 1999. Generation of superoxide in cardiomyocytes during ischemia before reperfusion. Am. J. Physiol. 277: H2240-H2246. PMID:10600842.

Bolli, R., Jeroudi, M.O., Patel, B.S., Aruoma, O.I., Halliwell, B., Lai, E.K., et al. 1989. Marked reduction of free radical generation and contractile dysfunction by antioxidant therapy begun at the time of reperfusion. Evidence that myocardial "stunning" is a manifestation of reperfusion injury. Circ. Res. 65: 607-622. PMID:2548761.

Bolli, R., Triana, J.F., and Jeroudi, M.O. 1990. Prolonged impairment of coronary vasodilation after reversible ischemia. Evidence for microvascular "stunning." Circ. Res. 67: 332-343. PMID:2376075.

Calabresi, L., Rossoni, G., Gomaraschi, M., Sisto, F., Berti, F., and Franceschini, G. 2003. High-density lipoproteins protect isolated rat hearts from ischemia-reperfusion injury by reducing cardiac tumor necrosis factor-alpha content and enhancing prostaglandin release. Circ. Res. 92: 330-337. doi:10.1161/01.RES. 0000054201.60308.1A. PMID:12595346.

Cao, C.M., Xia, Q., Zhang, X., Xu, W.H., Jiang, H.D., and Chen, J.Z. 2003. Salvia miltiorrhiza attenuates the changes in contrac- 
tion and intracellular calcium induced by anoxia and reoxygenation in rat cardiomyocytes. Life Sci. 72: 2451-2463. doi:10. 1016/S0024-3205(03)00142-5. PMID:12650853.

Chocron, S., Alwan, K., Toubin, G., Kantelip, B., Clement, F., Kantelip, J.P., et al. 1996. Effects of myocardial ischemia on the release of cardiac troponin I in isolated rat hearts. J. Thorac. Cardiovasc. Surg. 112: 508-513. doi:10.1016/S0022-5223(96) 70279-9. PMID:8751520.

Das, D.K., and Maulik, N. 2006. Cardiac genomic response following preconditioning stimulus. Cardiovasc. Res. 70: 254-263. doi:10.1016/j.cardiores.2006.02.023. PMID:16566910.

Duda, M., Konior, A., Klemenska, E., and Beresewicz, A. 2007. Preconditioning protects endothelium by preventing ET-1induced activation of NADPH oxidase and xanthine oxidase in post-ischemic heart. J. Mol. Cell. Cardiol. 42: 400-410. doi:10. 1016/j.yjmcc.2006.10.014. PMID:17156794.

Ebel, D., Schlack, W., Comfere, T., Preckel, B., and Thamer, V. 1999. Effect of propofol on reperfusion injury after regional ischaemia in the isolated rat heart. Br. J. Anaesth. 83: 903-908. PMID:10700791.

Fung, K.P., Zeng, L.H., Wu, J., Wong, H.N., Lee, C.M., Hon, P.M., et al. 1993. Demonstration of the myocardial salvage effect of lithospermic acid B isolated from the aqueous extract of Salvia miltiorrhiza. Life Sci. 52: PL239-PL244. doi:10.1016/ 0024-3205(93)90471-E. PMID:8492636.

Kevin, L.G., Novalija, E., and Stowe, D.F. 2005. Reactive oxygen species as mediators of cardiac injury and protection: the relevance to anesthesia practice. Anesth. Analg. 101: 1275-1287. doi:10.1213/01.ANE.0000180999.81013.D0. PMID:16243980.

Kokita, N., and Hara, A. 1996. Propofol attenuates hydrogen peroxide-induced mechanical and metabolic derangements in the isolated rat heart. Anesthesiology, 84: 117-127. doi:10. 1097/00000542-199601000-00014. PMID:8572324.

Lam, F.F., Yeung, J.H., Chan, K.M., and Or, P.M. 2007. Relaxant effects of danshen aqueous extract and its constituent danshensu on rat coronary artery are mediated by inhibition of calcium channels. Vascul. Pharmacol. 46: 271-277. doi:10.1016/j.vph. 2006.10.011. PMID:17188580.

Liu, G.T., Zhang, T.M., Wang, B.E., and Wang, Y.W. 1992. Protective action of seven natural phenolic compounds against peroxidative damage to biomembranes. Biochem. Pharmacol. 43: 147-152. doi:10.1016/0006-2952(92)90271-J. PMID:1739402.

Lopez-Ongil, S., Senchak, V., Saura, M., Zaragoza, C., Ames, M., Ballermann, B., et al. 2000. Superoxide regulation of endothelinconverting enzyme. J. Biol. Chem. 275: 26423-26427. doi:10. 1074/jbc.M000767200. PMID:10833511.

Mehlhorn, U., Krahwinkel, A., Geissler, H.J., LaRosee, K., Fischer, U.M., Klass, O., et al. 2003. Nitrotyrosine and 8-isoprostane formation indicate free radical-mediated injury in hearts of patients subjected to cardioplegia. J. Thorac. Cardiovasc. Surg. 125: 178-183. doi:10.1067/mtc.2003.97. PMID:12539002.

Morrow, J.D., and Roberts, L.J. 1997. The isoprostanes: unique bioactive products of lipid peroxidation. Prog. Lipid Res. 36: 1-21. doi:10.1016/S0163-7827(97)00001-5. PMID:9373618.

Murry, C.E., Jennings, R.B., and Reimer, K.A. 1986. Preconditioning with ischemia: a delay of lethal cell injury in ischemic myocardium. Circulation, 74: 1124-1136. PMID:3769170.

Neuzil, J., Rayner, B.S., Lowe, H.C., and Witting, P.K. 2005. Oxidative stress in myocardial ischaemia reperfusion injury: a renewed focus on a long-standing area of heart research. Redox Rep. 10: 187-197. doi:10.1179/135100005X57391. PMID:16259786.

Pagliaro, P., Gattullo, D., Rastaldo, R., and Losano, G. 2001. Ischemic preconditioning: from the first to the second window of protection. Life Sci. 69: 1-15. doi:10.1016/S0024-3205(01) 01113-4. PMID:11411799.
Piper, H.M., Abdallah, Y., and Schafer, C. 2004. The first minutes of reperfusion: a window of opportunity for cardioprotection. Cardiovasc. Res. 61: 365-371. doi:10.1016/j.cardiores.2003.12. 012. PMID: 14962469.

Qin, Q., Yang, X.M., Cui, L., Critz, S.D., Cohen, M.V., Browner, N.C., et al. 2004. Exogenous NO triggers preconditioning via a cGMP- and mitoKATP-dependent mechanism. Am. J. Physiol. Heart Circ. Physiol. 287: H712-H718. doi:10.1152/ajpheart. 00954.2003. PMID:15044194.

Ross, S., Munoz, H., Piriou, V., Ryder, W.A., and Foex, P. 1998. A comparison of the effects of fentanyl and propofol on left ventricular contractility during myocardial stunning. Acta Anaesthesiol. Scand. 42: 23-31. PMID:9580055.

Scarabelli, T., Stephanou, A., Rayment, N., Pasini, E., Comini, L., Curello, S., et al. 2001. Apoptosis of endothelial cells precedes myocyte cell apoptosis in ischemia/reperfusion injury. Circulation, 104: 253-256. PMID:11457740.

Ulus, A.T., Aksoyek, A., Ozkan, M., Katircioglu, S.F., and Basu, S. 2003. Cardiopulmonary bypass as a cause of free radicalinduced oxidative stress and enhanced blood-borne isoprostanes in humans. Free Radic. Biol. Med. 34: 911-917. doi:10.1016/ S0891-5849(03)00030-3. PMID:12654480.

Wang, Y., and Wang, D.H. 2004. Prevention of endothelin-1induced increases in blood pressure: role of endogenous CGRP. Am. J. Physiol. Heart Circ. Physiol. 287: H1868-H1874. doi:10. 1152/ajpheart.00241.2004. PMID:15205172.

Wu, T.W., Zeng, L.H., Fung, K.P., Wu, J., Pang, H., Grey, A.A., et al. 1993. Effect of sodium tanshinone IIA sulfonate in the rabbit myocardium and on human cardiomyocytes and vascular endothelial cells. Biochem. Pharmacol. 46: 2327-2332. doi:10. 1016/0006-2952(93)90624-6. PMID:8274165.

Xia, Z., Godin, D.V., and Ansley, D.M. 2003a. Propofol enhances ischemic tolerance of middle-aged rat hearts: effects on $15-\mathrm{F}(2 \mathrm{t})$ isoprostane formation and tissue antioxidant capacity. Cardiovasc. Res. 59: 113-121. doi:10.1016/S0008-6363(03)00351-1. PMID:12829182.

Xia, Z., Godin, D.V., Chang, T.K., and Ansley, D.M. 2003b. Dosedependent protection of cardiac function by propofol during ischemia and early reperfusion in rats: effects on 15-F2tisoprostane formation. Can. J. Physiol. Pharmacol. 81: 14-21. doi:10.1139/y02-170. PMID:12665253.

Xia, Z., Godin, D.V., and Ansley, D.M. 2004. Application of highdose propofol during ischemia improves postischemic function of rat hearts: effects on tissue antioxidant capacity. Can. J. Physiol. Pharmacol. 82: 919-926. doi:10.1139/y04-097. PMID:15573153.

Xia, Z., Kuo, K.H., Godin, D.V., Walker, M.J., Tao, M.C., and Ansley, D.M. 2005. 15-F(2t)-isoprostane exacerbates myocardial ischemia-reperfusion injury of isolated rat hearts. Am. J. Physiol. Heart Circ. Physiol. 289: H1366-H1372. doi:10.1152/ ajpheart.00042.2005. PMID:15937102.

Yagi, A., Fujimoto, K., Tanonaka, K., Hirai, K., and Takeo, S. 1989. Possible active components of tan-shen (Salvia miltiorrhiza) for protection of the myocardium against ischemiainduced derangements. Planta Med. 55: 51-54. doi:10.1055/s2006-961824. PMID:2717690.

Zhou, W., and Ruigrok, T.J. 1990. Protective effect of danshen during myocardial ischemia and reperfusion: an isolated rat heart study. Am. J. Chin. Med. 18: 19-24. doi:10.1142/ S0192415X90000046. PMID:2239811.

Zhou, L., Zuo, Z., and Chow, M.S. 2005. Danshen: an overview of its chemistry, pharmacology, pharmacokinetics, and clinical use. J. Clin. Pharmacol. 45: 1345-1359. doi:10.1177/0091270005282630. PMID:16291709. 